\title{
7. ASOCIACIONISMO, PARTICIPACIÓN CIUDADANA Y POLÍTICAS LOCALES: PLANTEAMIENTO TEÓRICO Y UNA EXPERIENCIA PRÁCTICA EN JAÉN*
}

\author{
Associations, citizen involvement and local policies: a \\ theoretical framework and a practical experience in Jaén
}

\author{
TOMÁs Alberich Nistal** \\ M. ángeles EsPadAs AlCÁZAR***
}

\section{Resumen}

El artículo presenta en primer lugar algunos aspectos teóricos sobre la participación ciudadana y el asociacionismo (relación con las políticas sociales, definiciones conceptuales, tipos y niveles, evolución en España...) para, en segundo lugar, realizar un resumen de la metodología y aspectos más significativos de la investigación llevada a

* Recibido: 14/12/2010

Revisado: 22/12/2010

Aceptado: 17/01/2011

La investigación relatada en el artículo se realizó con la colaboración de CIMAS (Observatorio Internacional de Ciudadanía y Medio Ambiente Sostenible) y el Ayuntamiento de Jaén (Concejalía de Participación Ciudadana).

Presentado parcialmente en el libro de los mismos autores (2010): Ser parte y tomar parte. Análisis y propuestas sobre asociacionismo y participación ciudadana en la ciudad de Jaén. Universidad de Jaén (169 págs.).

* Tomás Alberich Nistal

Doctor en Sociología. Profesor del Área de Trabajo Social y Servicios Sociales (Departamento Psicología). Universidad de Jaén.

Edificio C 5, despacho 111

Tel. (+34) 953211843

Campus Las Lagunillas, 23071 Jaén (España)

E-mail: alberich@ujaen.es

*** M. ${ }^{a}$ Ángeles Espadas Alcázar

Doctora en Sociología. Profesora del Área de Trabajo Social y Servicios Sociales (Departamento Psicología). Universidad de Jaén.

E-mail:espadas@ujaen.es 
cabo por los autores en la ciudad de Jaén, aplicando técnicas cuantitativas, cualitativas y participativas. Finalmente se recogen los aspectos más relevantes de las conclusiones y algunas recomendaciones para trabajar con asociaciones y promover la participación ciudadana en un municipio.

Palabras clave: Servicios Sociales, estado de bienestar, participación ciudadana, participación social, asociaciones no lucrativas, tercer sector.

\begin{abstract}
The article begins by presenting some theoretical aspects on citizenship involvement and associations (in relation to social policies, concept definitions, typology and levels, evolution in Spain...) in order to then, elaborate a summary of the methodology and most significative aspects of the research work carried out by the authors in the city of Jaén, implementing quantitative, qualitative and participative techniques. Finally some relevant aspects of the analysis of the conclusions are discussed and some recommendations to work with associations and to promote civil participation in a municipality are given.
\end{abstract}

Keywords: social services, welfare state, citizen involvement, social participation, associations and nonprofit third sectors.

\title{
1. Estado de bienestar, Políticas Sociales y participación de los ciudadanos
}

Ya en los años setenta del pasado siglo algunos autores plantearon la revisión del creciente Estado de Bienestar. A raíz de las sucesivas crisis del petróleo, las posiciones más liberales (los que después llamaríamos neoliberales) propugnan una reducción del Estado bajo los argumentos de reducir el gasto público y conseguir un mayor protagonismo de la sociedad civil. Pero uno de los problemas que se nos plantean en las Ciencias Sociales es cómo se define este polisémico concepto. Para los nuevos liberales, es todo lo que no es Estado y propugna aumentar el protagonismo social y económico tanto de las familias y asociaciones ciudadanas como el de las empresas, corporaciones, etc.

En la década de 1980 también desde las posiciones socialdemócratas se plantea que no todo funciona bien en los Estados de Bienestar: centralismo y jerarquización excesiva, burocracia, aumento del gasto público o falta de participación ciudadana directa. Todo ello estaba provocando -entre otros efectospasividad social y apoliticismo. Los años ochenta fueron protagonizados en el mundo anglosajón por las posiciones radicales de Thatcher y Reagan, con un desmantelamiento paulatino, pero claro y creciente, del Estado de Bienestar (privatizaciones, recortes de derechos laborales y sindicales, reducción de servicios públicos...). Este proceso se acelera a partir de la desaparición de la URSS como bloque antagónico (1989). Como alternativa pragmática a estos 
postulados radicales surge la denominada tercera vía (Anthony Giddens) como la superación de las posiciones más conservadoras de los neoliberales y de las clásicas de socialdemócratas/laboristas y también un cierto retorno a la sociedad civil. De estas posiciones surgirán propuestas políticas como la de Toni Blair o la de Felipe González en España que -con sus matices en cada caso- van desde un cierta «socialdemocracia de centro» hasta posiciones más socio liberales. En el caso español, se darán en los años ochenta, cuando aún se están construyendo aspectos básicos del Estado de Bienestar. Estos planteamientos acceden al poder de los gobiernos de diferentes países europeos a lo largo de las décadas de 1980 y 1990 y propugnan modelos de Estado pluralistas, esto es, resituar los roles de los distintos actores sociales y ampliar el horizonte hacia un mayor protagonismo de otras iniciativas en la gestión de servicios públicos, de modo que se acentúa la necesidad de mayor participación de los ciudadanos. Desde nuestro punto de vista, hay aquí una cuestión central para analizar: se puede abogar por la descentralización, la participación y la gestión menos burocrática de los servicios públicos y la «vuelta a la sociedad civil» desde muy distintos intereses e ideologías. En cualquier caso, si durante un largo periodo, cuando hablábamos de la implementación de las políticas sociales, nos referíamos casi exclusivamente a los sistemas de la administración pública, hoy es ineludible prestar atención al análisis de los otros dos sectores y a las relaciones que se dan entre ellos.

Para entender la evolución del papel de la participación ciudadana en el desarrollo de las políticas públicas es necesario detenerse, aunque sea brevemente, en el papel de los municipios, y recordar que nuestras administraciones públicas locales -gestores principales de muchos servicios públicos- tienen menos competencias y menor autonomía económica que las de su entorno europeo. Aunque hoy parezca sorprendente para muchos jóvenes, la mayoría de los ayuntamientos españoles, aun bien entrada la década de 1970, se dedicaban casi exclusivamente al urbanismo, a ordenar el tráfico, la limpieza urbana y poco más. La cultura (excepto fiestas patronales), el deporte, los servicios sociales (excepto cierta asistencia social), el empleo... no existían como concejalías, ni como departamentos que tuvieran que gestionar o atender. Mucho menos los que se han denominado servicios personales o dirigidos a grupos específicos de población, ya que las concejalías de juventud, mujer, mayores o inmigración, se crearon posteriormente. Muchos de estos servicios estaban siendo atendidos por las asociaciones vecinales, por la ayuda mutua comunal y por las redes familiares o, simplemente, no se atendían. A partir de la década de 1970 buena parte de las asociaciones se crearon, precisamente, como una forma de auto-organización para atender las demandas ciudadanas. Esquemáticamente, la evolución en las últimas décadas en España ha sido la que describimos en el siguiente cuadro. 


\section{Cuadro 1. Asociacionismo y políticas sociales locales. Resumen de la evolución en España}

\begin{tabular}{|c|c|c|c|}
\hline Décadas & $\begin{array}{l}\text { Asociacionismo y } \\
\text { movimientos sociales } \\
\text { más significativos }\end{array}$ & $\begin{array}{l}\text { Predominio en las } \\
\text { políticas locales }\end{array}$ & $\begin{array}{l}\text { Servicios } \\
\text { sociales }\end{array}$ \\
\hline 1960 & $\begin{array}{l}\text { Asociaciones de } \\
\text { Cabezas de Familia y } \\
\text { de Amas de Casa } \\
\text { (1964: Ley de } \\
\text { Asociaciones). }\end{array}$ & $\begin{array}{l}\text { Urbanismo y poco más. } \\
\text { Confrontación con los } \\
\text { movimientos sociales. } \\
\text { Ideologías cerradas. } \\
\text { Jerarquización política } \\
\text { y social. }\end{array}$ & $\begin{array}{l}\text { Beneficencia y } \\
\text { Asistencia Social } \\
\text { (asistencialismo). } \\
\text { Estado «autoritario» } \\
\text { del Bienestar. }\end{array}$ \\
\hline 1970 & $\begin{array}{l}\text { Predominan las } \\
\text { Asociaciones de } \\
\text { Vecinos y los sindicatos. } \\
\text { Se crean de Padres de } \\
\text { Alumnos (APA), clubs } \\
\text { parroquiales, casas } \\
\text { regionales, culturales, } \\
\text { cine-clubs... } \\
\text { Acción unitaria en cada } \\
\text { barrio. } \\
\text { Relación directa entre } \\
\text { acción local (mejora de } \\
\text { mi barrio) y acción } \\
\text { política global } \\
\text { (conseguir la } \\
\text { democracia en España). }\end{array}$ & $\begin{array}{l}\text { 1978: Constitución } \\
\text { Española, garantiza la } \\
\text { autonomía de los } \\
\text { municipios (art. 140). } \\
\text { 1979: primeras } \\
\text { elecciones democráticas } \\
\text { municipales. }\end{array}$ & \\
\hline 1980 & $\begin{array}{l}\text { Crisis de los } \\
\text { movimientos sociales } \\
\text { locales y de las } \\
\text { ideologías tradicionales } \\
\text { de las izquierdas. } \\
\text { Fomento del } \\
\text { minifundismo asociativo } \\
\text { corporativista } \\
\text { especializado por temas. } \\
\text { Creación de asoc. } \\
\text { ecologistas, feministas, } \\
\text { cultural-deportivas. }\end{array}$ & $\begin{array}{l}\text { Política del «ladrillo»: } \\
\text { construcción de nuevas } \\
\text { infraestructuras y } \\
\text { equipamientos. } \\
\text { Comienzo del } \\
\text { desembarco en cultura, } \\
\text { fiestas, servicios } \\
\text { sociales, deporte, etc. } \\
\text { Comienzo de la } \\
\text { especialización } \\
\text { corporativa temática. } \\
\text { Competencia desleal. }\end{array}$ & $\begin{array}{l}\text { De «Insuficiencia de } \\
\text { Recursos/Derecho } \\
\text { condicionado» se avanza } \\
\text { hacia el Estado de } \\
\text { Bienestar, con Servicios } \\
\text { Sociales como Derecho } \\
\text { Universal. Estructura } \\
\text { jerárquica piramidal. } \\
\text { Plan concertado de } \\
\text { SS.SS. }\end{array}$ \\
\hline
\end{tabular}




\begin{tabular}{|c|c|c|c|}
\hline Décadas & $\begin{array}{l}\text { Asociacionismo y } \\
\text { movimientos sociales } \\
\text { más significativos }\end{array}$ & $\begin{array}{l}\text { Predominio en las } \\
\text { políticas locales }\end{array}$ & $\begin{array}{l}\text { Servicios } \\
\text { sociales }\end{array}$ \\
\hline 1980 & $\begin{array}{l}\text { estudiantiles, } 3 .^{\text {a }} \text { edad... } \\
\text { Aumento del número de } \\
\text { socios y de los servicios } \\
\text { prestados, lo que } \\
\text { permite una mejor } \\
\text { financiación. Creación } \\
\text { de federaciones y } \\
\text { confederaciones. }\end{array}$ & $\begin{array}{l}\text { a las asociaciones. } \\
\text { Creación de Consejos } \\
\text { de Participación (1985: } \\
\text { Ley Local LRBRL. } \\
\text { Estatuto del Vecino). } \\
\text { Económicamente los } \\
\text { Ayuntamientos quedan } \\
\text { como la Administración, } \\
\text { pobre frente a las } \\
\text { Autonomías. }\end{array}$ & \\
\hline 1990 & $\begin{array}{l}\text { Asociaciones de } \\
\text { Voluntariado, ONG y } \\
\text { «Tercer Sector» } \\
\text { Asociaciones de servicios } \\
\text { y modelo asociación- } \\
\text { empresa. Fundaciones, } \\
\text { asoc. asistenciales, ocio... } \\
\text { Nuevas federaciones y } \\
\text { plataformas unitarias. } \\
\text { Nuevos movimientos } \\
\text { (0,7\%, ONGD...). } \\
\text { Ideologías abiertas. } \\
\text { Leyes de Voluntariado } \\
\text { (1996) y regulación de } \\
\text { las fundaciones y del } \\
\text { mecenazgo (1994, } \\
\text { reformadas en 2002). }\end{array}$ & $\begin{array}{l}\text { Continuación en la } \\
\text { creación de nuevas } \\
\text { concejalías específicas } \\
\text { de juventud, mujer, } 3^{\text {a }} \\
\text { edad, empleo y } \\
\text { desarrollo local... } \\
\text { Descubrimiento del } \\
\text { voluntariado. } \\
\text { Privatizaciones, reducción } \\
\text { del gasto público. } \\
\text { Globalización. } \\
\text { Redacción de planes } \\
\text { integrales sectoriales } \\
\text { (para contrarrestar la } \\
\text { sectorialización) y de } \\
\text { planes estratégicos en } \\
\text { diversas ciudades. } \\
\text { Pérdida de derechos } \\
\text { (laborales, sociales...) } \\
\text { o derechos difusos en } \\
\text { una sociedad de } \\
\text { la precariedad y de la } \\
\text { modernidad líquida en } \\
\text { la que una parte de la } \\
\text { población «sobra» } \\
\text { (Bauman, 2005). }\end{array}$ & $\begin{array}{l}\text { Legislación Autonómica } \\
\text { de Servicios Sociales. } \\
\text { Estructura jerárquica. } \\
\text { Las corporaciones } \\
\text { locales dependen de las } \\
\text { CC. AA., que se reservan } \\
\text { las competencias y } \\
\text { recursos. }\end{array}$ \\
\hline
\end{tabular}




\begin{tabular}{|c|c|c|c|}
\hline Décadas & $\begin{array}{l}\text { Asociacionismo y } \\
\text { movimientos sociales } \\
\text { más significativos }\end{array}$ & $\begin{array}{l}\text { Predominio en las } \\
\text { políticas locales }\end{array}$ & $\begin{array}{l}\text { Servicios } \\
\text { sociales }\end{array}$ \\
\hline 2000 & $\begin{array}{l}\text { ONL oenegeización y } \\
\text { redes } \\
\text { Redes de asociaciones } \\
\text { y movimientos. } \\
\text { Comunicación e } \\
\text { información: Internet, } \\
\text { páginas web y TIC. } \\
\text { Se quiere dar un nuevo } \\
\text { papel a las asociaciones, } \\
\text { ONG y ONGD. } \\
\text { Movimientos } \\
\text { antiglobalización. } \\
\text { Escándalos de } \\
\text { corrupción y fraude en } \\
\text { ONG (Intervida, } \\
\text { Anesvad...), falta de } \\
\text { transparencia. } \\
\text { Propuestas de códigos } \\
\text { éticos. } \\
\text { Responsabilidad Social } \\
\text { Corporativa (RSC) de } \\
\text { las empresas, grupos de } \\
\text { interés y stakeholders. } \\
\text { (2002: Ley de } \\
\text { Asociaciones). }\end{array}$ & $\begin{array}{l}\text { Redes de municipios. } \\
\text { Más privatizaciones y } \\
\text { adjudicación a } \\
\text { asociaciones. Sociedad } \\
\text { de la Información y del } \\
\text { Conocimiento. } \\
\text { Redacción de Agendas } \\
21 . \\
\text { Modelos de integración } \\
\text { social relacional, calidad } \\
\text { total... y conceptos } \\
\text { nuevos (o } \\
\text { redefiniciones): } \\
\text { gobernanza, ciudadanía } \\
\text { (activa e inclusiva), } \\
\text { empoderamiento, } \\
\text { corresponsabilidad } \\
\text { social, capital social. } \\
\text { Crecimiento con boom } \\
\text { inmobiliario } \\
\text { especulativo hasta } 2008 \\
\text { (2003: Reforma de la } \\
\text { LRBRL haciéndola más } \\
\text { presidencialista. Regula } \\
\text { la iniciativa popular). }\end{array}$ & $\begin{array}{l}\text { Duplicidad de redes de } \\
\text { asistencia: «redes para } \\
\text { enredarse», } \\
\text { «privatización social» } \\
\text { de los servicios } \\
\text { públicos. } \\
\text { Ley estatal de la } \\
\text { Dependencia (2006). } \\
\text { Se favorece la } \\
\text { privatización (casi el } \\
\text { 80\% de las plazas de } \\
\text { residencias son ya } \\
\text { privadas o concertadas) } \\
\text { El perfil del usuario de } \\
\text { SS. SS. cambia y se } \\
\text { amplía (inmigración, } \\
\text { clases medias...). }\end{array}$ \\
\hline
\end{tabular}

Fuente: Elaboración propia.

Las dos últimas décadas quedan definidas por:

- 1990: Privatizaciones, reducción del gasto público. Globalización. Nuevos movimientos de solidaridad, ideologías abiertas. Redacción de planes estratégicos sectoriales (p. ej. de Servicios Sociales) en un contexto de aparentes y permanentes cambios acelerados (TIC, i $+\mathrm{d}+\mathrm{i} \ldots$ ). Pérdida de derechos (laborales, sociales...) o derechos difusos en una sociedad de la precariedad y de la «modernidad líquida» en la que, como nos indica Zigmun Barman (2005), una parte de la población «sobra».

- 2000: oenegeización y redes. Los Estados quieren dar un nuevo papel a las asociaciones y ONG. Se propugna la Sociedad de la Información y del Conocimiento y un modelo de integración social relacional. Ante la situación de 
crisis sociales y políticas sucesivas y la disminución de derechos, se plantea la recuperación de derechos pasando del Estado de Bienestar a la Sociedad de Bienestar. Se consolidan conceptos como gobernanza y empoderamiento, dirigidos a dar un mayor protagonismo a la sociedad y a las organizaciones sociales pero con diferentes matices e ideologías (menos Estado y apoyo a ONG, ONL, fundaciones privadas, boom de la Responsabilidad Social Corporativa ...). La población que «sobra» aumenta a partir del comienzo de la crisis en 2007.

En nuestra realidad profesional actual, los Servicios Sociales (y muchos otros sistemas de protección) son gestionados por entidades o departamentos del Ayuntamiento, la Diputación, la Comunidad Autónoma, el Estado... pero cada vez más por empresas privadas, asociaciones y fundaciones. Se configura una nueva administración pública relacional y nuevas redes de servicios superpuestas y sobrepuestas. Nos preguntamos: ¿redes de seguridad o redes que sirven para enredarse? Desde nuestro punto de vista, la gestión -de hecho- de algunos servicios (p. ej. los Servicios Sociales) hace que estos sean percibidos por los ciudadanos como un complejo entramado de dobles y triples redes de atención en el que la cadena de responsabilidades se alarga, se diluye, haciéndose muy difícil su identificación institucional, así como la participación y el control por parte de los ciudadanos (Espadas, 2006: 274). Se necesita, por tanto, una diferenciación y clarificación de derechos reconocidos con responsabilidades (públicas y privadas) claras. Las redes y el recurrir a una mayor participación de los ciudadanos y de sus organizaciones en la gestión de servicios no pueden servir para diluir responsabilidades ni para sustituir a la red pública. Desde nuestro punto de vista, este no es el objetivo de la participación social ni de la participación ciudadana, como veremos en el epígrafe siguiente.

\section{Participación Ciudadana y Participación Social}

En este contexto, cabe preguntarnos: ¿hablamos todos de lo mismo cuando hablamos de participación? En la actualidad, la palabra «participación» tiene una carga valorativa muy positiva. La participación y lo participativo se han convertido en atributos deseables para cualquier iniciativa, proyecto o proceso social. Se utilizan de modo recurrente como principio inspirador de leyes, reglamentos y estatutos de organizaciones. Hoy en día, son un requerimiento metodológico generalizado para el desarrollo de la planificación social, independientemente de la pertinencia, el contenido y el significado que realmente se le otorgue en cada caso. Cabría entonces preguntarse: ¿hablamos todos de lo mismo cuando hablamos de participación? A continuación exponemos algunas referencias conceptuales que pueden ser útiles para reflexionar sobre el tema. 


\subsection{La participación como mecanismo de desarrollo de una ciudadanía activa e} inclusiva

Si analizamos el abusivo recurrir al término participación encontramos que bajo este concepto se hace referencia a realidades, propósitos, estrategias e ideologías muy diversas, incluso a veces opuestas. A menudo se confunde una parte con el todo, esto es, llamar participación a alguno de sus niveles, por ejemplo, al más básico, como es la mera información pública. Pero, precisamente la participación ciudadana, cuando se refiere a tomar parte en los asuntos públicos, implica una mayor distribución del poder respecto de ellos ("tomar parte" del poder) y se convierte en un método de profundización democrática. Así entendida, la participación no se alcanza, ni mucho menos se agota, en la consecución de alguno de sus escalones: información, consulta, toma de decisiones o gestión colegiada. Cada uno de estos niveles forma parte de un continuum y a la vez requisitos para que la participación pueda desarrollarse. En función de los objetivos que la participación persiga, del nivel que se logre y del papel que desempeñen los ciudadanos, podemos hablar de participación plena, participación incompleta o incluso de pseudoparticipación, Desde nuestro punto de vista, los «tipos ideales» de los modelos de participación y pseudoparticipación se caracterizarían del siguiente modo:

\section{Cuadro 2: Referente participativo}

\begin{tabular}{|l|l|}
\hline \multicolumn{1}{|c|}{ PSEUDOPARTICIPACIÓN } & \multicolumn{1}{c|}{ PARTICIPACIÓN } \\
\hline De «arriba hacia abajo». & De «abajo hacia arriba». \\
\hline Como concesión. & Como derecho. \\
\hline Despolitizada. & Politizada. \\
\hline $\begin{array}{l}\text { Como fin en sí misma } \\
\text { («lo importante es participar»). }\end{array}$ & $\begin{array}{l}\text { Como fin y como medio («es importante } \\
\text { participar para lograr algo»). }\end{array}$ \\
\hline En el marco de la administración. & $\begin{array}{l}\text { En la administración y en los espacios } \\
\text { comunitarios. }\end{array}$ \\
\hline Puntual. & Procesual. \\
\hline Centralizada. & Descentralizada. \\
\hline Informativa o consultiva. & $\begin{array}{l}\text { Ejecutiva (toma de decisiones, planificación, } \\
\text { ejecución y evaluación de los procesos o } \\
\text { proyectos). }\end{array}$ \\
\hline No vinculante. & Vinculante. \\
\hline Limitada aspectos o temas «menores». & En todas las áreas de la organización. \\
\hline
\end{tabular}




\begin{tabular}{|l|l|}
\hline \multicolumn{1}{|c|}{ PSEUDOPARTICIPACIÓN } & \multicolumn{1}{c|}{ PARTICIPACIÓN } \\
\hline $\begin{array}{l}\text { Hegemonía de los directivos, técnicos } \\
\text { o políticos. }\end{array}$ & $\begin{array}{l}\text { Todos los miembros de la organización, } \\
\text { incluyendo a voluntarios y afectados, son } \\
\text { protagonistas. Técnicos, directivos o } \\
\text { políticos como mediadores y facilitadores. }\end{array}$ \\
\hline Sucesión de individualidades. & Acción colectiva. \\
\hline $\begin{array}{l}\text { Como estrategia de marketing } \\
\text { o «espectáculo». }\end{array}$ & Efectiva y en el «día a día» de la entidad. \\
\hline $\begin{array}{l}\text { Mediante consumo de actividades } \\
\text { puntuales. }\end{array}$ & $\begin{array}{l}\text { Adecuando las estructuras de la } \\
\text { organización. }\end{array}$ \\
\hline
\end{tabular}

Fuente: López de Aguileta (1990) añadiendo y modificando algunas dimensiones.

Desde la pseudoparticipación hasta la participación plena tendríamos un gradiente, diferentes posibilidades y escalones, como vemos en el gráfico 1. Lo que se da con más frecuencia es la desinformación y la pseudoparticipación (base de la pirámide: área de la no participación). En el área de la participación tendríamos primero, y con cierta frecuencia, la información, después (en menos casos) las prácticas de consulta y debate y, solo en contadas experiencias, la transparencia y el control democrático eficiente y, aún en menos, la cogestión o toma de decisiones conjunta.

Figura 1: De la pseudoparticipación al poder participativo

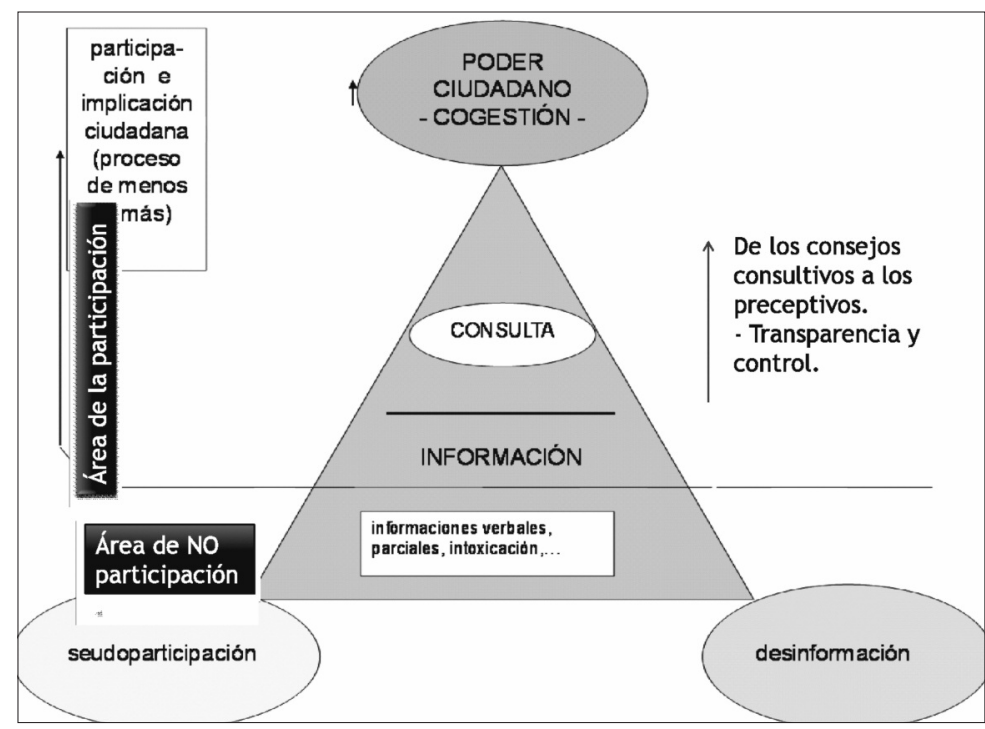

Fuente: Elaboración propia. 
Hay que tener en cuenta que no siempre es posible llegar a la participación colegiada en la gestión y en algunos casos tal vez ni siquiera sea conveniente. No todos podemos participar en todo. Hay que diferenciar ámbitos. No es lo mismo un Centro de Servicios Sociales Comunitarios, un Centro Cultural o un equipamiento de barrio que un centro especializado o un teatro nacional. Por ejemplo, en la gestión de un hospital o de un centro de investigación será posible la participación en determinados ámbitos (Junta de Personal/Comité de Empresa, elección de cargos, control democrático de la gestión general y control del gasto...) pero no en otros aspectos profesionales. La participación directa se podrá plantear en cada nivel y según competencias profesionales. Estos aspectos sobre en qué «se puede/debe» participar y en qué no, son esenciales en el debate. La participación en la cúspide de la pirámide será más fácil y factible en centros pequeños, y en políticas concretas. También será la más "política», especialmente en la medida en que el ámbito de actuación sea mayor, al ser también necesaria una intervención más global y comprometida. Pero esto no significa que la participación mayor -la autogestión- más factible en centros pequeños elimine la posibilidad de la participación directa en ámbitos globales y complejos. En estos ámbitos grandes (por ejemplo, la elaboración de los presupuestos de una ciudad) también es posible la participación directa y la implicación ciudadana (presupuestos participativos, consejos preceptivos, transparencia...) buscando la combinación equilibrada de técnicas y fórmulas, por ejemplo mediante autoreglamentos consensuados que favorezcan la participación ciudadana individual (referendos, asambleas, presentación de iniciativas populares...) y la colectiva (asociaciones, consejos...).

Volviendo a la concepción de participación que queremos desarrollar, es importante recordar que en el momento actual, caracterizado por claros síntomas de desafección de los ciudadanos a participar en los asuntos públicos, se trataría de avanzar en la consolidación de una concepción de ciudadanía activa que pueda generar un tipo de identidad en la que los ciudadanos se reconozcan y de la que se sientan parte integrante y activa, de modo que podamos responder colectivamente a los retos que nos afectan a todos (Benedicto y Morán, 2002). A esta última y renovada concepción de ciudadanía activa como forma de acción colectiva, nos referimos cuando hablamos de ciudadanía activa e inclusiva y la vinculamos a la concepción de participación que planteamos. Desde esta concepción, la participación no es un fin en sí mismo: lo importante no es participar, sino hacerlo para conseguir unos objetivos. En este sentido, la participación ciudadana es un mecanismo de profundización democrática. Así pues, el concepto de participación se despliega en dos dimensiones: ser parte de algo y tomar parte en algo. Para el caso de la ciudadanía, estas son dos condiciones fundamentales 
que la posibilitan, esto es: la pertenencia y su ejercicio activo. Para tomar parte en algo activamente es fundamental pertenecer a ello y por eso hablamos de un modelo de ciudadanía inclusiva que amplíe las posibilidades de participación de las personas. Esto requiere la extensión a otros ciudadanos de los derechos que ya disfrutan algunos, e implica un modelo de participación social en el que no solo luchamos por la defensa de nuestros intereses más cercanos y particulares ni los de nuestro grupo sino que, trascendiéndolos, existe un referente de interés social.

Asimismo, hablamos de ciudadanía activa porque esta perspectiva se refiere a un modelo en el que las personas y sus organizaciones no solo pertenecen formalmente a una comunidad sino que intervienen activamente en ella a través de diferentes cauces, de entre los cuales uno importante es el voto, pero desde luego no es el único.

\subsection{Los conceptos de Participación Ciudadana y Participación Social}

La Participación Ciudadana deriva de una contradicción en el ámbito del poder. Se plantea en la medida en que existe un poder (Estado, Gobierno, Administración Pública) y un no poder (ciudadanos) que quieren participar, es decir «tomar parte» o ejercer algún aspecto de ese poder y, en definitiva, tener más poder (ya sea mediante la información, el control, la consulta, etc.). Participar es tomar parte en algo donde hay diferentes partes y «ser partícipe de». Podemos definir la Participación Ciudadana como el conjunto de actividades, procesos y técnicas por los que la población interviene en los asuntos públicos que le afectan.

Así, si participar es tomar parte en algo donde hay diferentes partes (administración/administrados...) la relación dependerá del poder que tenga cada parte. Si el poder de unos es total y el de los otros casi nulo, la participación será muy difícil. Será algo graciable que se otorga por los que ostentan el poder. Un sistema es más democrático en la medida en que los ciudadanos tienen -individual y colectivamente- poder como tales; no son meros súbditos y son por tanto más sujetos activos (y menos objetos pasivos). En definitiva, en las sociedades complejas, la participación persigue que los habitantes de un lugar sean más sujetos sociales, con más capacidad para transformar el medio en que viven y de control sobre sus órganos políticos, económicos y administrativos.

A diferencia de la participación ciudadana, la participación social es un concepto más amplio y difuso, relacionado con la acción colectiva. Podemos entender por Participación Social cualquier acto, fenómeno o proceso colectivo de participación de la sociedad. Existen actividades que no consideramos par- 
ticipación ciudadana pero que sí serían formas de participación social. Actos tan diferentes como la asistencia a espectáculos (culturales, deportivos...) y actividades públicas (reuniones, conferencias...), la participación en actividades y órganos corporativos (colegios profesionales, comunidades de vecinos), en iglesias y credos religiosos o en partidos políticos, nos estarían indicando qué participación social y qué tejido social se da en un determinado espacio pero no necesariamente serían indicadores de la participación ciudadana. Incluso el grado de asociacionismo y de participación comunitaria también reflejan el nivel de participación social pero no necesariamente lo que hemos definido como participación ciudadana. El que en una ciudad o barrio haya más o menos participación en los actos que se convoquen (ya sea la convocatoria realizada por una organización política, religiosa o asociativa) nos indicará la participación social. Si estos actos son exclusivamente corporativos o internos, ideológicos o de ocio y entretenimiento, no lo podemos considerar de por sí como participación ciudadana. Ahora bien, si en estas entidades, organismos o convocatorias se tratan los problemas públicos que afectan a la comunidad o a la ciudad, o son actos reivindicativos ante la Administración para debatir propuestas, iniciativas, alternativas o cualquier otro aspecto o asunto que afecte a un grupo de población o a la comunidad, entonces podemos considerar que forman parte de la participación ciudadana. La participación ciudadana sería una parte de la participación social, la que afecta directamente a la comunidad y se ejerce en relación con la Administración pública.

Para mejorar el funcionamiento de la democracia local es conveniente que haya participación social y un tejido social activo e intenso. Es un punto de partida. Pero los gobiernos y las administraciones públicas se deben preocupar especialmente por la participación ciudadana. ¿Cómo hacerlo? ¿En qué aspectos, de qué manera y mediante qué mecanismos?

\section{Una propuesta de investigación y de desarrollo del asociacionismo y la participación ciudadana}

El caso que presentamos se refiere a una investigación desarrollada en la ciudad de Jaén en 2008 y 2009. Su origen era una iniciativa de la Administración municipal interesada en dinamizar el tejido social de la ciudad y en desarrollar una política de participación ciudadana que fuese participativa. En este caso, el desarrollo de las jornadas, talleres y de la investigación que aquí referimos solo supone una primera fase de lo que debiera ser un proceso más amplio de planificación participativa de un plan municipal de Participación Ciudadana. Presentamos aquí únicamente algunas cuestiones de índole metodológica que pueden servir como orientaciones para saber «por dónde empezar» en el caso 
de investigaciones en otros municipios, así como algunas recomendaciones generales para técnicos, políticos y miembros del tejido social que pueden ser útiles a la hora de poner en marcha iniciativas de participación ciudadana y de trabajar con las asociaciones. ${ }^{1}$

Para estudiar el asociacionismo y la participación ciudadana en un municipio determinado, obviamente el diseño de la investigación está mediado por la concepción de participación ciudadana de la que se parte y que, en nuestro caso, venimos subrayando tanto aquí como en trabajos anteriores. Lógicamente, el diseño de una investigación también viene marcado por el acuerdo al que se llegue con los patrocinadores. En este caso se trataba de llevar a cabo un diagnóstico que ayudara a plantear posteriormente estrategias para dinamizar el tejido social de la ciudad y a poner en práctica una política participativa, precisamente en materia de participación ciudadana. En definitiva, esto responde a un interés por desarrollar una nueva cultura política y ciudadana de profundización democrática que exige cambios profundos en el modelo de relaciones entre las administraciones públicas y los ciudadanos.

Desde nuestro punto de vista, el diseño de una política municipal de participación ciudadana que quiera ser participativa, realista y con vocación de continuidad requiere conocer la situación actual de los principales actores y cauces de participación. Por otro lado, tener un tejido social y asociativo activo, ya que esto es a la vez un medio y un requisito para desarrollar esa nueva cultura cívico-política. Pero también requiere otra cuestión primordial: la incorporación activa, y desde el principio, de los vecinos y de sus organizaciones, tanto en el diagnóstico de la realidad como en el posterior diseño y planificación, así como en el impulso de nuevas formas de participación y en la toma de decisiones.

\subsection{Objetivos y planteamiento metodológico}

Para conocer aspectos fundamentales de la participación social es necesario estudiar qué asociacionismo tenemos, de qué tipos, formas y contenidos. Solo el análisis cualitativo nos aportará información sobre qué participación se da, dentro y fuera de las asociaciones, entre ellas y con la ciudad, para conocer sus límites, características y potencialidades. Es necesario saber cómo se ven las asociacionesa sí mismas, cómo se quieren ver, cómo son vistas, cómo piensan que se ven. También si son o pueden ser agentes de cambio, escuelas de democracia o ciudadanía o qué valores quieren transmitir (visión y misión de las entidades).

1. El grueso de la investigación puede consultarse en Espadas y Alberich, 2010 
Para el caso de Jaén nos plantemos los siguientes objetivos generales:

- Dinamizar la participación ciudadana, impulsando procesos de análisis, debate y reflexión conjunta en las asociaciones, entre las diferentes asociaciones y organizaciones sociales y entre estas y la Administración municipal.

- Promover la participación de los ciudadanos y de las asociaciones en el diseño y ejecución de la política municipal y en los planes de desarrollo local, buscando y planteando la colaboración de los tres sectores -público, privado y social- en el desarrollo local.

Estos se concretaron en los siguientes objetivos específicos:

1. Conocer la percepción de los problemas de la ciudad, especialmente desde el ámbito asociativo.

2. Realizar un diagnóstico de la realidad asociativa de la ciudad de Jaén, tanto desde el punto de vista cuantitativo como cualitativo.

3. Conocer las necesidades de las asociaciones, así como las demandas sobre la actuación municipal en materia de participación.

Los objetivos 2 y 3 se concretan en cinco dimensiones de análisis complementarias que es necesario investigar:

a. Dimensión cuantitativa de las asociaciones (número y tipo, tamaño, locales y sedes, actividades y servicios que prestan...).

b. Participación interna de las asociaciones (modos de producción de decisiones; metodología de trabajo interno; nivel de implicación y participación de los socios; tipología de actividades que desarrollan...).

c. Participación en la vida del barrio/ciudad (arraigo comunitario, implicación en la vida del barrio, en organización de actividades...).

d. Relaciones con otras organizaciones (establecimiento de redes, protocolos de colaboración y coordinación; comunicación y relaciones informales, etc.).

e. Relación con el Ayuntamiento y con otras Administraciones públicas (grado y tipo de relación con el Ayuntamiento y con otras Administraciones; representación en los Consejos locales u otros órganos, propuestas e iniciativas presentadas...).

4. Plantear propuestas y estrategias de actuación viables para llevar a cabo desde el Ayuntamiento (Concejalía de Participación Ciudadana, servicios de atención al público, comunicación, información...).

Para este estudio realizamos un planteamiento metodológico plural combinando perspectivas de investigación complementarias, a saber: cuantitativa, cualitativa y participativa. Se concretaron en tres tipos análisis: 
- Análisis cuantitativo, a partir de los datos de distintos registros: el General de Asociaciones de la Junta de Andalucía, el de la Concejalía de Participación Ciudadana, la Guía de Recursos Sociales de Jaén (Alberich et al., 2009) y del trabajo de campo directo.

- Análisis de los discursos, producidos mediante entrevistas semidirigidas a los distintos actores: responsables políticos, técnicos municipales y miembros del movimiento asociativo (directivos, socios, técnicos, vecinos...).

- Diagnóstico participativo: es decir, un análisis por parte de las asociaciones de temas centrales; devolución y contraste de información y detección de necesidades mediante la realización de talleres con las asociaciones.

La utilización de la entrevista semidirigida, además de la adecuación a los objetivos planteados, ofrece un valor añadido muy importante para desarrollar procesos participativos ya que, en muchos casos, la interacción que se produce entre entrevistador y entrevistado puede propiciar y facilitar la implicación y el acercamiento de las asociaciones y más aún cuando se trata de estudios que forman parte de proyectos de dinamización o participación social de más largo alcance. Además, al realizarse la mayoría de las entrevistas en los espacios propios de los entrevistados se favorece también la observación directa por parte del investigador del funcionamiento cotidiano de las asociaciones.

En cuanto a las técnicas participativas y de devolución de información a los ciudadanos, estas, obviamente, son el pilar tecnológico cuando se investiga desde un paradigma participativo o cuando el diagnóstico de una realidad es un eslabón dentro de un proceso de participación social. No obstante, a la hora de realizar el diseño es importante adoptar una postura realista respecto de sus posibilidades de aplicación. Es imprescindible tener en cuenta tanto los condicionantes temporales que implica su utilización (procesos de larga duración) como los económicos (requieren una dedicación intensiva de técnicos y dinamizadores cualificados). En nuestro caso se utilizaron solo algunas técnicas participativas. En un primer momento, en la fase previa de la investigación, se realizaron talleres y debates con los ciudadanos y con el tejido asociativo de la ciudad, realizados en el marco más amplio de dos jornadas sobre Participación Ciudadana. En ellas se debatió sobre la situación del «mundo asociativo» de la ciudad (primer diagnóstico participativo), sobre las necesidades, carencias, propuestas... de las asociaciones y sobre la participación ciudadana, presentándose también los objetivos de la investigación. Se utilizó el trabajo en grupos pequeños mediante la técnica DAFO y el debate en gran grupo y asamblea. El material y las conclusiones de dichas jornadas sirvieron para plantear los enfoques, hipótesis y objetivos específicos de la investigación. Además, la realización de este tipo de actividades es muy recomendable pues, en otro orden 
de cosas, facilitan el encuentro entre asociaciones, entre estas y la Administración y entre estas y el equipo investigador o grupo motor, y favorecen la implicación del tejido social desde el momento inicial de diseño de un proceso participativo.

Posteriormente se realizó un taller-panel de devolución y contraste de las conclusiones provisionales de la investigación con representantes de las asociaciones. Finalmente, se convocó un acto de presentación pública abierto a todos los colectivos de la ciudad en el que tuvo lugar un nuevo debate abierto a partir de las conclusiones.

\subsection{Diagnóstico y propuestas para dinamizar la Participación Social en un municipio}

El diagnóstico sobre el asociacionismo y la participación ciudadana que hemos realizado sobre la ciudad de Jaén, aunque tiene algunas singularidades, comparte, no obstante, muchos rasgos con la realidad más general del asociacionismo en Andalucía y España. Por ello, entendemos que las propuestas aquí recogidas también pueden ser útiles para muchos otros municipios españoles en los que la participación social presenta características muy parecidas. Precisamente el discurso, muchas veces citado, de «aquí es que las cosas son diferentes», «es que lo que ocurre en esta ciudad no ocurre en ningún sitio...», son frases muy parecidas al discurso que se observa de modo recurrente en otros lugares, donde también se piensa en sentido negativo que priman las diferencias (locales y sectoriales) y las deficiencias.

- Aspectos cuantitativos y tipologías del asociacionismo

El número total de asociaciones en la ciudad de Jaén (116.000 habitantes) es de 360 asociaciones registradas y activas (o al menos «vivas» -en el sentido de tener una sede social, correspondencia, asistir a algunos actos...-). A pesar de la heterogeneidad de criterios de las fuentes de registro, si comparamos Andalucía y España con otros ámbitos geográficos, el número de asociaciones de Jaén es relativamente menor. Existe una gran pluralidad y diversidad asociativa. No hay un tipo predominante; en todas las áreas o temas hay muchas entidades. Sobresalen Educación (por las AMPA especialmente), Cultura, Acción Social (destacando las relacionadas con la discapacidad) y las nuevas entidades relacionadas con el Deporte y la Salud. Las Asociaciones de Vecinos también ocupan un lugar destacado, cubriendo todos los barrios de la ciudad; es importante que se siga creando nuevas asociaciones de vecinos (en total hay 39). La presencia de asociaciones creadas a partir de la década de 1980, como las 
Juveniles y de Mujeres, también es significativa. Esta cantidad y diversidad asociativa puede ser considerada excesiva en algunas áreas, por caerse en un cierto «minifundismo asociativo». No obstante, la posible debilidad que puede producir una excesiva fragmentación en muchas asociaciones pequeñas es solo relativa, ya que puede verse compensada por la creciente creación de federaciones y de nuevas entidades unitarias, como plataformas, redes y también experiencias de actividades o recursos compartidos.

- Puntos fuertes y débiles del asociacionismo y la participación ciudadana Atendiendo al análisis final de los datos de la investigación hemos identificado una serie de debilidades y fortalezas sobre diferentes aspectos, que sintetizamos a continuación.

\section{Visión e identidad de la ciudad}

Factores que dificultan la participación social: existe una baja estima de la ciudad y de sus posibilidades, en parte porque se identifica calidad de vida con nivel económico o renta per cápita. Además hay una falta de arraigo por parte de un sector de ciudadanos que la viven como una ciudad de «tránsito» o como ciudad «de lunes a viernes» cuestión que propicia la baja implicación social de una parte significativa de la población.

Paralelamente existen una serie de factores que pueden favorecer la participación como: la cercanía, familiaridad, tamaño «abarcable»; menos prisas y estrés que en las grandes ciudades y por tanto «más tiempo para mirar alrededor y para ver las cosas». También el que «está todo por hacerse» favorece la visibilidad de lo que se hace. Hay facilidad para el encuentro, la coincidencia, el contacto entre asociaciones, cuestiones que facilitan la coordinación y el trabajo conjunto.

\section{Visión del asociacionismo de la ciudad}

El número de asociaciones no es un indicador sólido de la «vida» asociativa: muchas de ellas apenas funcionan. Tampoco lo es de la participación ciudadana; otras muchas desarrollan un modelo de participación interna y de implicación con la ciudad muy endeble. Predominan dos tipos de estructuras organizativas: unas pocas grandes entidades con muchos socios inscritos pero poco activos; y multitud de pequeñas organizaciones con pocos socios, poco coordinadas, aisladas y con escasas actuaciones integrales de participación y cooperación. Ambas estructuras desfavorecen la participación y el contacto activo con la ciudadanía. Unas por ser demasiado jerárquicas y superespecia- 
lizadas, las otras por llegar a poca gente y tener una acción fragmentada en la ciudad. El tejido asociativo tiene un bajo perfil de activismo, de reivindicación y movilización, persistiendo en muchas entidades rasgos de dependencia y clientelismo político. Las entidades tienen culturas organizativas muy diferentes y referentes teóricos sobre asociacionismo y participación muy distintos. Como consecuencia, existe una real dificultad para articular las diferencias entre las asociaciones y entre estas y la Administración. Además, existe una utilización partidista de la participación ciudadana y un predominio del modelo de participación centrado en el consumo de actividades de ocio, cultura y entretenimiento o prestación de servicios asistenciales.

Como contrapartida encontramos una creciente conciencia sobre la importancia de la independencia de las asociaciones como elemento de estabilidad, continuidad y credibilidad social, además del potencial de incidencia social del asociacionismo. Observamos voluntad de una parte importante del tejido asociativo por trabajar sumando esfuerzos, creando sinergias, hacer trabajo conjunto, y de un reciente número de asociaciones dispuestas a tomar parte en proyectos innovadores que se están concretando en nuevas experiencias de coordinación y proyectos singulares de participación. En especial destaca un significativo y plural número de asociaciones activas (vecinales, culturales, acción social...) desde el punto de vista de la implicación en la vida de la ciudad, con una visión que trasciende sus intereses propios.

\section{Funcionamiento y participación de las asociaciones}

Existe una gran dificultad para conectar con el ciudadano «de a pie» y muchas asociaciones con escasa base social, poca visibilidad e incidencia. También, como aspecto negativo, existen agudos déficit de participación interna y falta de implicación de los socios en la toma de decisiones, en el trabajo, etc. Hay también un presidencialismo y delegación excesiva en las juntas directivas y dificultades de relevo en las mismas además de dificultades también para la delegación, coordinación y el trabajo en equipo. Predomina la participación puntual, coyuntural e individualizada. Se detecta también un efecto perverso de la profesionalización y burocratización creciente de las asociaciones que «deja fuera de juego» a algunos miembros y dificulta la asunción de responsabilidades por su parte. Es significativa la dificultad para integrar distintas categorías sociales en algunas asociaciones (mujeres, jóvenes). Otra cuestión importante es la falta e inadecuación de recursos, que se agudiza por la resistencia a compartir recursos y equipamientos. En síntesis, hay una baja relación interasociativa y de creación de sinergias, con excesiva búsqueda de protagonismo y competencia entre asociaciones. Esto se contrarresta con fortalezas como la amplia experiencia asociativa de muchas entidades y conocimiento sobre asociacionismo y la 
participación social. También crece el número de asociaciones con una perspectiva amplia e integral de la participación y de asociaciones que desarrollan formas participativas de toma de decisiones y de trabajo interno. La profesionalización y formación creciente puede, a medio plazo, favorecer la planificación del trabajo, la evaluación y mejora de la calidad, darle mayor visibilidad e integrar a más gente en las asociaciones (siempre que se sepan delimitar adecuadamente los ámbitos profesionales y del voluntariado). También se observan algunas experiencias interesantes de ampliación y profundización del papel de las mujeres en el tejido asociativo, así como de las asociaciones dispuestas a relacionarse y a compartir proyectos y recursos.

\section{Relaciones con la Administración}

Los puntos débiles sobre este tema están marcados por el escaso interés de los poderes públicos por desarrollar políticas participativas efectivas. Las actuaciones públicas se centran en temas «menores». Existe una falta de proyectos con continuidad y a largo plazo por parte de la Administración, de un modelo de financiación adecuado y del necesario apoyo técnico y «acompañamiento» a las asociaciones. Asimismo, vemos la nula rendición de cuentas y evaluación del impacto de lo realizado. Existe una distancia creciente entre los discursos de los responsables políticos y las prácticas cotidianas de la Administración que provoca desencanto, escepticismo ciudadano y desmotivación ante el escaso interés por desarrollar la participación ciudadana que demuestra la Administración. De nuevo aparece la mutua utilización y relación clientelista entre las asociaciones y la Administración, al no haber unos cauces «reales» de participación y de órganos formales. Aun asi observamos en los últimos años cierta receptividad y mayor sensibilidad de la Administración hacia iniciativas innovadoras y procesos de participación social. Una parte del tejido asociativo no renuncia a un modelo amplio y efectivo de participación, y reivindica espacios de decisión, lo que constituye un síntoma de «vida» del tejido social. También hay buena disposición para colaborar con la Administración de una parte importante de las asociaciones. Otro rasgo interesante es que existen experiencias recientes de colaboración entre asociaciones y otras administraciones (proyecto de redes sociales para la participación ciudadana; creación de centros de recursos para asociaciones...).

\section{Algunas consideraciones para trabajar con asociaciones y promover la participación ciudadana}

A partir de las conclusiones de este y de otros trabajos que venimos desarrollando en los últimos años en materia de asociacionismo y participación ciu- 
dadana, resumimos a continuación algunas consideraciones de carácter general que creemos que, con frecuencia, por evidentes, se obvian. En ese sentido, pensamos que es importante explicitarlas y tenerlas en consideración, tanto por parte de los poderes públicos, como de los técnicos y de las organizaciones ciudadanas a la hora de trabajar con y en los movimientos y redes ciudadanas.

\subsection{Conocer las dificultades pero trabajar sobre las potencialidades}

A pesar de que una parte importante del tejido asociativo tiene de sí mismo una visón negativa respecto del papel que juega, de su representatividad, de su capacidad de interlocución en la ciudad y de su implicación en los asuntos públicos, creemos que para desarrollar cualquier proceso de dinamización social es importante conocer los posibles déficit y dificultades pero para avanzar, hay que centrarse en las potencialidades.

Si atendemos al nivel de actividad de las asociaciones, la situación de Jaén se caracteriza por existir un gran número de asociaciones que, aunque legalmente lo son y están inscritas en los diferentes registros, su nivel de actividad es prácticamente inexistente o muy bajo. Son entidades muy difíciles de localizar, apenas se las conoce en su entrono más próximo y, desde el punto de vista de la participación ciudadana y de su implicación en la vida social de la ciudad, sus aportaciones pueden considerarse nulas. Comprendería a asociaciones de todo tipo: culturales, recreativas, de vecinos... Para trabajar con estas entidades es útil iniciar estrategias diferenciadas y específicas sobre información, formación, dinamización, acompañamiento e implicación.

Por otra parte, hay otro gran bloque conformado por muchas y muy heterogéneas organizaciones. Agruparía a las entidades que sí pueden considerarse activas. Estas realizan actividades con cierta regularidad y son identificadas y conocidas -como mínimo- por su entorno social cercano o en su ámbito de actuación. Incluye entidades activas o muy activas, pero el perfil de participación de este gran bloque es más diverso.

Si atendemos a la implicación y participación en la vida de la ciudad existen asociaciones con una actividad considerable pero «hacia dentro» de la propia organización o en defensa de intereses más o menos particulares o muy ceñidos al tema-área de actuación al que se dedican. Solo de modo minoritario encontramos asociaciones de diverso tipo (vecinales, culturales, de acción social...) que son activas desde el punto de vista de la participación ciudadana; esto es, entidades implicadas en la vida de la ciudad, con una visión que va más allá de sus problemas o intereses como asociación y que, además del tema central del que se ocupan, tienen una acentuada orientación cívico-ciudadana y un referente más claro de participación social que el resto de entidades. Es importante subrayar que, dentro de estas últimas, existe un pequeño grupo (20-25) que, inde- 
pendientemente de que realicen o no tareas asistenciales o de gestión de servicios y de que sean vecinales o sectoriales, tienen una perspectiva menos asistencial del asociacionismo y más de desarrollo de funciones cívico-expresivas y de transformación social. Estas son las más optimistas respecto de la ciudad y sus posibilidades para desarrollar proyectos creativos y respecto de las potencialidades de la participación social. También son las asociaciones más críticas y autocríticas con el modelo dominante de asociacionismo, caracterizado por la escasa participación e incidencia en la vida pública, falta de base social real y de participación interna. Comparten con otras (especialmente con algunas asociaciones de vecinos muy activas y de bastante significación por su trayectoria en la ciudad), un planteamiento de cierta crítica hacia los aspectos generales del papel de la Administración respecto del asociacionismo y la participación ciudadana, en el sentido de parecerles insuficientes los cauces y recursos existentes. Pero a la vez son pragmáticas y constructivas en el «día a día». Colaboran mucho con las administraciones y también se sirven (y dependen) de modo muy considerable de los recursos de esta (que en muchas ocasiones saben buscar, captar y optimizar mejor que el resto de asociaciones).

Podemos afirmar, por tanto, que existen al menos unas 20 o 25 asociaciones que tienen un papel muy activo, dispuestas a colaborar en proyectos innovadores y que comparten una visión muy parecida de la participación ciudadana, entendida esta como una actividad cívico-política, como un mecanismo de profundización democrática que va más allá de los objetivos concretos de la actividad de su asociación.

Desde nuestro punto de vista, el que solo exista un pequeño grupo de asociaciones muy activas (que por otra parte es una situación muy parecida a la que se da en muchos municipios españoles), siendo una cuestión que inicialmente puede interpretarse como una situación negativa es, no obstante, un factor importante para tener en cuenta por las potencialidades que presenta desde el punto de vista de dinamizar la participación ciudadana en una localidad. Nos referimos a que este grupo podría configurarse como un grupo motor que establezca estrategias, alianzas y «conjuntos de acción» con otros actores (ya sean asociaciones formales menos activas, ya sectores y redes informales) que, desde referentes distintos pero no opuestos, puedan iniciar procesos de dinamización e implicación social.

Así, hemos observado que, por encima de otras características como el tamaño, la antigüedad, el barrio o área de actuación, lo que incide más en el tipo y en la calidad de las prácticas participativas que desarrollan las asociaciones es el referente y la visión del concepto de participación que mantengan. Por eso consideramos que, para activar la participación ciudadana, una estrategia ineludible debe ser desarrollar estas cuestiones mediante la formación, las escuelas de ciudadanía, foros y espacios de encuentro, etc. entre asociaciones y entre los vecinos en general. 
Figura 2: Asociacionismo de Jaén: tipología y posibles conjuntos de acción

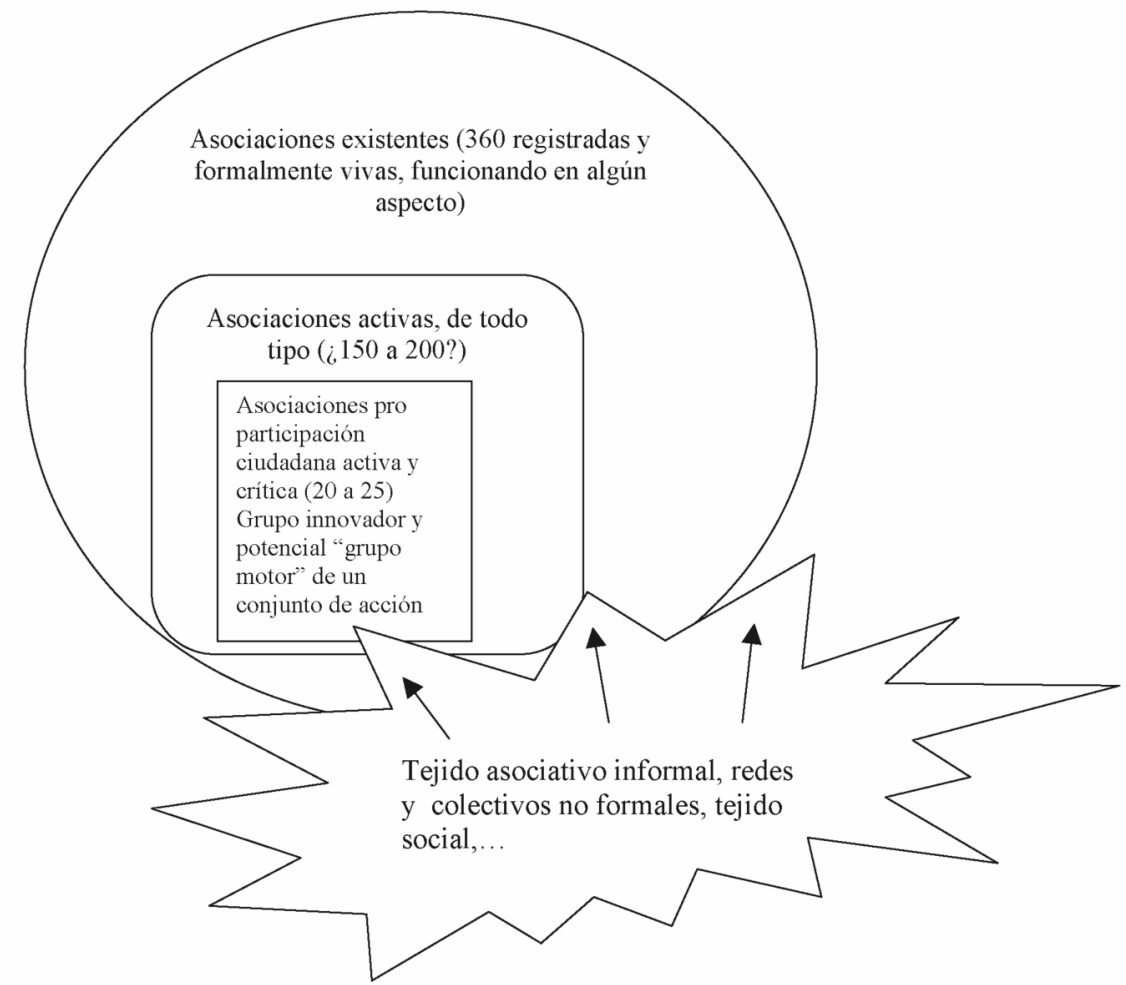

Fuente: Elaboración propia.

\subsection{Dificultades para desarrollar la participación ciudadana en un contexto} históricamente condicionado por la ausencia de planificación y la utilización partidista de la participación

Es muy frecuente que la política de participación se haya desarrollado a base de actuaciones puntuales, incluso en muchas ocasiones guiada por intereses partidistas o condicionada por intereses corporativos. En cualquier caso, suele ser un área residual dentro de la Administración, carente de un plan general de actuación y, por consiguiente, de un presupuesto sólido, de los especialistas necesarios y de los recursos suficientes. En este contexto, un gobierno municipal que quiera mejorar y ampliar la calidad democrática de sus actuaciones debe definir claramente los objetivos y líneas que quiere seguir en materia de participación ciudadana. Para ello es necesario elaborar un Plan de Participación recogiendo de modo integral el conjunto de estrategias y actuaciones que se van a llevar a cabo 
para promover la presencia de los ciudadanos en los asuntos públicos. Si además se quiere avanzar hacia formas de democracia participativa es necesario que el diseño de ese Plan incluya esos objetivos de un modo realista pero efectivo .

\subsection{Trabajar con asociaciones partiendo de una situación de competencia y conflicto}

Las relaciones en torno a la participación ciudadana en Jaén, como en cualquier municipio, no están exentas de tensiones y conflictos. El trabajo cotidiano con entidades muy diferentes y que a menudo tienen referentes muy distantes de lo que es la participación suele ser fuente de tensiones pero a su vez también es un indicador de que el tejido social está «vivo» y de que hay vida asociativa en la ciudad. La ausencia de conflictos no siempre es un indicador positivo, ya que también puede serlo de una escasa o nula actividad (en el interior de una asociación, en la relación de esta con el barrio, en las relaciones con otras asociaciones, con los políticos y con la administración....) o de situaciones de falta de democracia efectiva que no toleran el conflicto.

El reconocimiento de esas situaciones con el mayor grado de normalidad posible, en el sentido de que son fruto de las relaciones de proximidad y del trabajo cotidiano, es un requisito y un medio importante para iniciar un nuevo marco de relaciones. Para ello es muy útil que los distintos actores implicados puedan identificar los puntos críticos de conflicto sin llegar a «romper la baraja». Probablemente las tensiones se hayan producido por unos temas determinados, situaciones concretas, entre entidades determinadas o incluso con el propio Ayuntamiento. Es importante, por tanto, iniciar, impulsar y favorecer desde la Administración estrategias que, reconociendo las diferencias en lo puntual, tiendan a trascender esos aspectos y busquen puntos de contacto y de consenso entre y con las asociaciones. No se trataría de que una parte intente vencer ni convencer a otra, sino de buscar y subrayar los puntos de acuerdo, relativizando los desacuerdos.

\section{Tetralema de posiciones de los discursos}

Existen técnicas que ayudan a analizar situaciones conflictivas y que son útiles para trabajar sobre discursos contrapuestos. Una de ellas es la denominada por J. Galtung y T. R. Villasante tetralema (Villasante, 2006). Exponemos a continuación en qué consiste de modo muy breve, mediante un ejemplo de posiciones discursivas del análisis realizado.

Estamos acostumbrados a pensar en modelos contrapuestos o en posiciones enfrentadas ante un problema, a elegir entre «blanco o negro»y, como mucho, pensar en una escala de grises, de posiciones intermedias. Pero las 
prácticas sociales nos indican que, ante muchos problemas, la complejidad no se puede resumir en solo dos posiciones y las intermedias entre ambas. Hay otras posturas que, partiendo de otras lógicas, nos pueden plantear diferentes vías de acción. Los tetralemas, como decíamos, nos ayudan a visualizar y trabajar sobre conflictos y discursos diferentes o contrapuestos. Se trata de encontrar al menos otras dos alternativas diferentes a las -en principio- enfrentadas, trabajando sobre cuatro posiciones posibles.

Ante el papel de las asociaciones en la ciudad y en la democracia local tenemos dos posiciones principales: quienes defienden que las asociaciones son representativas de la ciudadanía y son «la conciencia de la ciudad» y quienes, desde algunas asociaciones pero sobre todo desde la Administración, sostienen que los únicos legitimados para representar a los ciudadanos son los concejales elegidos en las elecciones y que, por tanto, cualquier mecanismo de participación debe ser solo consultivo. Pero los discursos y las posibilidades de la participación ciudadana no se pueden limitar a estos dos; hay al menos otras dos posiciones. Lo vemos en el siguiente tetralema:

Figura 3: Discursos sobre el papel de las asociaciones y la participación ciudadana

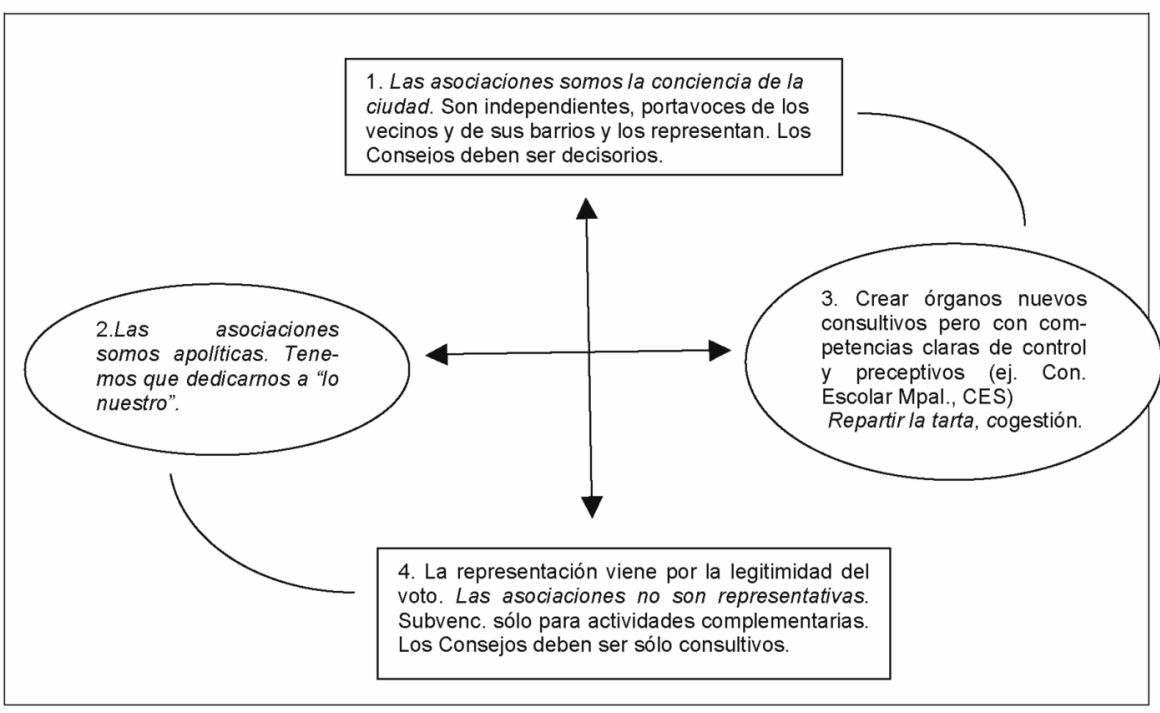

Fuente: Elaboración propia.

Los discursos de las posiciones 1 y 4 son los tradicionalmente enfrentados. Los de la 2 y 3 también. Los de la 2 (asociaciones apolíticas) y 4 (administración), se complementan. Los discursos de la 1 (posición radical asociativa) y 3 (po- 
sición pragmática) pueden buscar fácilmente puntos en común, por ejemplo, creando un foro de asociaciones y presionando a las administraciones para que los órganos de participación que se creen sean eficaces. Como vemos, se pueden buscar así posiciones «superadoras» de los discursos habituales, que animen a la acción y a buscar alternativas, más allá de las tradicionales o las simples posiciones intermedias.

\subsection{Sobre el trabajo con asociaciones con diferentes culturas organizativas}

A la luz del análisis realizado es importante tener en cuenta las diferentes sensibilidades (transformadoras, conservadoras,) trayectorias (unas recién creadas, otras con más de 25 años de antigüedad), niveles de trabajo (desde formadas solo por socios-activistas hasta las que tienen profesionales contratados) objetivos (asistenciales, cívico-políticos...) y expectativas de las asociaciones. En síntesis, es primordial tener presente la pluralidad de culturas organizativas de las asociaciones y los objetivos que se plantean respecto a la participación ciudadana así como lo que están dispuestas a hacer. Por tanto, para desarrollar una política participativa en la que tome parte un amplio número de entidades es necesario desarrollar proyectos que permitan que con esas culturas organizativas muy distintas se sientan cómodas entre ellas y con el Ayuntamiento. Se trataría de que se conociesen más y creasen conjuntos de acción entre las que se sientan identificadas por algún aspecto común o complementario. No todas tienen que integrarse en un mismo proyecto pero sí debería haber iniciativas adecuadas para que todas pudiesen tomar parte en alguno. Una de las iniciativas para trabajar en el conocimiento y desarrollo de espacios compartidos puede ser la creación de un foro de asociaciones. Explicamos a continuación de modo breve los rasgos fundamentales de esta idea.

\section{- Foro de asociaciones}

Esta propuesta se articula en torno la idea de impulsar la creación de nuevos cauces de participación social complementarios a órganos de participación ciudadana, como los consejos locales.

Un foro de asociaciones puede entenderse como un espacio de encuentro y colaboración entre asociaciones en el que, por ejemplo, cada cierto tiempo se ponga en común el trabajo que hace cada una, lo que puede aportar y ofrecer a las demás o lo que necesitaría. También serviría como entidad de coordinación de estrategias conjuntas, para compartir información, recursos... En definitiva, podría plantearse como un espacio de colaboración que ayude a superar las dinámicas de competencia entre asociaciones. Puede desarrollarse 
mediante encuentros y sesiones de trabajo y complementarse en el «día a día» mediante TIC (lista de distribución por correo-e, blogs, webs, etc.).

El Foro de Asociaciones puede impulsar un cambio de mentalidad respecto a la concepción dominante de participación ciudadana. Implica y consigue pasar de la competencia a la colaboración entre asociaciones (cuestión especialmente importante cuando hay escasez de recursos y de personal). Supone superar el modelo de «feria de asociaciones» (no su dimensión lúdica sino en el sentido de espectáculo-escaparate, marketing, actuación puntual, espacio institucionalizado; organización y protagonismo de la Administración) e ir hacia el «foro»: más operativo, más continuidad y periodicidad, trabajar para conseguir objetivos concretos; menos institucionalizado, la Administración como facilitador-impulsor y las asociaciones como protagonistas.

Ambas estructuras, Foros y Consejos, son necesarias en el caso que hemos estudiado y en cualquier municipio de unas ciertas dimensiones. Pueden ser complementarias en su acción y producir sinergias en el impulso de la participación ciudadana.

Cuadro 3: Diferencias básicas entre Foro de Asociaciones y Consejos Locales

\begin{tabular}{|l|l|}
\hline \multicolumn{1}{|c|}{ FORO } & \multicolumn{1}{c|}{ CONSEJO DE PARTICIPACIÓN } \\
\hline - Menos institucional & $\bullet$ Formal, institucional \\
\hline $\begin{array}{l}\text { - No representativo, para quien } \\
\text { quiera participar }\end{array}$ & $\bullet$ Teóricamente representativo \\
\hline $\begin{array}{l}\text { Espacio de colaboración propio } \\
\text { de las asociaciones }\end{array}$ & $\begin{array}{l}\text { Cauce formal de participación } \\
\text { de las asociaciones con el } \\
\text { Ayuntamiento }\end{array}$ \\
\hline $\begin{array}{l}\text { Cauce de participación } \\
\text { complementario a los Consejos }\end{array}$ \\
\hline
\end{tabular}

Fuente: Elaboración propia.

\subsection{Mantenimiento de la credibilidad y rendición de cuentas}

Para que las asociaciones se impliquen en la vida de la ciudad y en proyectos de participación social, la propia Administración tiene que garantizar su credibilidad de un modo suficientemente amplio. Una de las explicaciones más frecuentes sobre los déficit de participación es que los ciudadanos no suelen creer que, movilizándose y asociándose, pueden cambiar las cosas. Pero esto se agudiza con el poco convencimiento real que a veces tiene la propia administración y fruto de ello, las pocas posibilidades de tomar parte que los responsables políticos dejan a los ciudadanosen ese sentido. Por eso, una propuesta 
que amplíe la credibilidad de los nuevos discursos a favor de la participación pasa no solo por dar más voz a los movimientos ciudadanos e implicarlos más en los asuntos de la ciudad sino también por la evaluación y rendición de cuentas de lo que se lleva a cabo en cada área de competencia. En este sentido, los órganos institucionales de participación, como los consejos, pueden jugar un papel fundamental.

En definitiva queremos subrayar que, como en cualquier otra área de competencia y responsabilidad pública, la política de Participación Ciudadana no puede improvisarse técnica ni económicamente. Requiere una planificación y unos recursos estables acordes con los objetivos de esta. Una política de participación ciudadana que tenga vocación de continuidad y de credibilidad no puede ser un recurso al que se acude cuando hay falta de medios económicos o cuando se requiere el apoyo ciudadano para un tema concreto. Como hemos visto a lo largo todo este trabajo, a pesar -o quizás precisamente- por los déficit de participación existentes en la sociedad actual, los propios ciudadanos cada vez tienen más clara la necesidad de un nuevo modelo de relaciones con la Administración. Desde nuestro punto de vista, la participación ciudadana tiene que jugar un papel fundamental en la construcción de ese nuevo modelo.

\section{Referencias bibliográficas}

Alberich Nistal, T. (2006). Guía fácil de Asociaciones, Manual de Gestión para la creación, desarrollo y dinamización de entidades no lucrativas (4. ${ }^{a}$ edición). Madrid: Dykinson.

Alberich Nistal, T. (2008). IAP, Redes y Mapas Sociales: desde la investigación a la intervención social. Revista de Trabajo Social Portularia. Volumen VIII, n. ${ }^{\circ} 1$. Huelva: Universidad de Huelva.

Alberich et al. (2009). Guía de Recursos Sociales Ciudad de Jaén. Jaén: Patronato Municipal de Asuntos Sociales del Ayuntamiento de Jaén.

Arnstein, S. R. (1969). A Ladder of Citizen Participation. JAIP, vol. 35, n. ${ }^{\circ} .4$, julio 1969 (citado por Linares, 2008).

Bauman, Z. (2003). Comunidad. En busca de seguridad en un mundo hostil. Madrid: Siglo XXI.

Bauman, Z. (2005). Vidas desperdiciadas. La modernidad y sus parias. Barcelona: Paidós Estado y Sociedad.

Benedicto, J. y Morán, M. L. (2002). La construcción de la ciudadanía activa entre los jóvenes. Consultado en http:/www.imjuve.mtas.es

Cembranos, Montesinos y Bustelo (1988). La animación sociocultural: una propuesta metodologica. Madrid: Editorial Popular.

Equipo CLAVES (1994). Gestión Participativa de las Asociaciones. Madrid: Editorial Popular. 
Espadas Alcázar, M. A. (2006). El Tercer Sector construyendo ciudadanía. La participación del Tercer Sector en los Servicios Sociales en Andalucía. Universidad Complutense de Madrid, Tesis Doctoral. Disponible en www.ucm.es/BUCM/tesis/cps/ ucm-t29504.pdf

Espadas Alcázar, M. A. (2001). La Participación Ciudadana en el sistema de Servicios Sociales: marco de referencia y perspectivas metodológicas. En VV. AA., Nuevas Perspectivas y líneas de investigación en Trabajo Social. Granada: EUTS Universidad de Jaén - Ed. Comares.

Espadas Alcázar, M. A. y Alberich, T. (2010). Ser parte y tomar parte. Análisis y propuestas sobre asociacionismo y participación ciudadana en la ciudad de Jaén. Jaén: Servicio de Publicaciones de la Universidad de Jaén.

Linares Márquez de Prado, E. (2008). Participación e intervención social contra la exclusión. Trabajo Social Hoy (monográfico sobre T.S. para la inclusión). Madrid: Colegio Oficial en Trabajo Social y AA.SS. de Madrid.

López de Aguileta, I. (1990). Estado, Sociedad Civil y procesos de participación. Documentación Social, n. ${ }^{\circ} 80$. Madrid.

Rodriguez Cabrero, G. (1991). Estado de Bienestar y Sociedad de Bienestar. Realidad e ideología.

Villasante, T. R. (2006). Desbordes creativos. Estilos y estrategias para la transformación social. Madrid: La Catarata. 